\title{
Disputas en torno al desarrollo y el territorio: el caso de Yasuní-ITT durante el Ecuador de la Revolución Ciudadana
}

Disputes over Development and Territory: The Case of Yasuni-ITT during Ecuador's Citizen Revolution.

Disputas em torno do desenvolvimento e território: o caso de Yasuni-ITT durante a Revolução Cidadã do Equador

Soledad Stoessel ${ }^{\star}$

Martín Scarpacci*

Recibido: 24 de octubre de 2019

Aprobado: 26 de junio de 2021

https://doi.org/10.12804/revistas.urosario.edu.co/territorios/a.8382

Para citar este artículo

Stoessel, S., \& Scarpacci, M. (2021). Disputas en torno al desarrollo y el territorio: el caso de Yasuní-ITT durante el Ecuador de la Revolución Ciudadana. Territorios, (45), 239-259. https://doi.org/10.12804/ revistas.urosario.edu.co/territorios/a.8382

\begin{abstract}
* Doctora en Ciencias Sociales (UNLP). Docente e investigadora en UNLP, FLACSO-Ecuador y CALAS Sede Regional Andes. Correo electrónico: soledad. sto@gmail.com. ORCID: https://orcid.org/00000003-1872-5758

** Doctorando en Planificación Urbana y Regional (IPPUR-UFRJ Brasil). Docente Visitante FLACSO-Ecuador, Investigador Centro de Politicas Públicas y Sociedad (UNR Argentina). Correo electrónico: martinescarpacci@gmail.com.ORCID: https://orcid.org/00000001-5955-2377
\end{abstract}


Palabras clave

Desarrollo; territorio; extractivismo; Estado; conflicto socio-territorial

Keywords

Development; territory; extractivism; State; socio-territorial conflict

Palavras-chave

Desenvolvimento; território; extrativismo; Estado; conflito socioterritorial

\section{territarias 45}

\section{RESUMEN}

Este artículo analiza la disputa en torno al desarrollo y territorio a partir del estudio de una política gubernamental conocida como Iniciativa Yasuní-ITT, implementada en 2007 por el proyecto de la Revolución Ciudadana en Ecuador. La Iniciativa fue abandonada en 2013, lo cual significó comenzar a explotar el petróleo de parte del territorio ITT ubicado en el Parque Nacional Yasuní. Esto provocó la activación de un conflicto social y territorial en el que participaron diversos colectivos ambientalistas, ONG, comunidades indígenas y el gobierno. El texto reconstruye la dinámica social de esta contienda e identifica los distintos discursos esgrimidos en torno a la problemática del desarrollo y del territorio. Se parte de una perspectiva teórica que combina el enfoque estratégico-relacional de Bob Jessop y un análisis espacial que entiende al territorio como un campo conflictivo de poder. El artículo concluye que la disputa en torno al extractivismo no puede abordarse sin considerar la dinámica procesual de la lógica de acumulación capitalista, ni de las estrategias que se dan los actores para apropiarse de los territorios.

\section{ABSTRACT}

The paper analyses the dispute over development and territory based on a study of a government policy known as the Yasuni-ITT Initiative implemented in 2007 by the Citizen's Revolution project in Ecuador. The Initiative was abandoned in 2013, which meant that part of the ITT territory located in Yasuni National Park was to be exploited for oil. This led to the activation of a social and territorial conflict involving various environmental collectives, NGOs, indigenous communities and the government. The text reconstructs this conflict and identifies the different discourses used around the problems of development and territory. The paper is based on a theoretical perspective that combines Bob Jessop's strategic-relational approach and a spatial analysis that understands territory as a conflictive field of power. The paper concludes that the dispute over extractivism cannot be addressed without considering the processual dynamics of the capitalist accumulation and the strategies that actors use to appropriate territories.

\section{RESUMO}

O texto analisa a disputa por desenvolvimento e território a partir do estudo de uma política governamental conhecida como Iniciativa Yasuní ITT implementada em 2007 pelo projeto Revolução Cidadã no Equador. A iniciativa foi abandonada em 2013, o que significava começar a explorar o petróleo de parte do território ITT localizado no Parque Nacional Yasuní. Isso levou à ativação de um conflito social e territorial no qual participaram vários grupos ambientalistas, ONG, comunidades indígenas e o governo. O texto reconstrói a dinâmica social dessa disputa e identifica os diferentes discursos utilizados em torno da problemática de desenvolvimento e do território. Parte-se de uma perspectiva teórica que combina a abordagem estratégico-relacional de Bob Jessop e uma análise espacial que entende o território como um campo conflituoso de poder. $\mathrm{O}$ artigo conclui que a disputa em torno do extrativismo não pode ser abordada sem considerar a dinâmica processual da lógica de acumulação capitalista ou as estratégias que os atores utilizam para se apropriar dos territórios. 


\section{Introducción}

La iniciativa Yasuní-ITT fue una de las propuestas más emblemáticas y novedosas del paradigma del "buen vivir" implementada por el proyecto político de la Revolución Ciudadana liderada por Rafael Correa, cuando llegó al poder presidencial en Ecuador en 2007. La iniciativa consistía en la decisión de no explotar un sector del Parque Nacional Yasuní que se encuentra en el corazón de la Amazonía ecuatoriana, a cambio de recibir una contribución financiera internacional. Esta iniciativa tenía distintos propósitos: desde conservar la biodiversidad, ofrecer soluciones al problema del cambio climático a nivel mundial, transformar la matriz productiva, basada hasta entonces en la explotación de los recursos naturales, y pasar hacia una matriz basada en el bioconocimiento; cambiar la matriz energética de forma tal que se dejara de depender del recurso petrolero, hasta respetar a los pueblos indígenas no contactados que habitan el territorio.

Sin embargo, en agosto de 2013, luego de seis años de que la iniciativa estuviera en curso, el gobierno nacional anunció la decisión de dejarla sin efecto y comenzar la explotación del territorio. Varios fueron los argumentos para realizarlo, pero en lo fundamental primó uno. Se sostuvo que ante el déficit de la contribución internacional de los países "centrales" a la iniciativa, debido al cual Ecuador no había recibido los aportes que se esperaban, no tenía otra opción que explotar una parte del Parque Nacional para continuar implementando una agenda orientada a la inclusión social y el desarrollo de las comunidades.

Esta decisión evidenció tanto los constreñimientos estructurales generados por la globalización capitalista (Marini, 2008) para llevar adelante agendas soberanas en los territorios nacionales, como los obstáculos derivados de las "selectividades estratégicas" inscritas en los Estados (Jessop, 2016). Con esta noción, Jessop alude al conjunto de patrones que atraviesan al terreno estatal en un momento determinado y que operan como restricciones u oportunidades, más allá del voluntarismo de los agentes que lo ocupen. Determinados legados institucionales (la morfología y funcionamiento estatal heredados históricamente y el entramado normativo, como las Constituciones), específicas matrices de poder instaladas a lo largo del tiempo y tipos modelos de desarrollo, constituyen aspectos inscritos en el terreno estatal, que pueden ser capitalizados -o, por el contrario, ser obstáculos - para alcanzar los intereses por parte de los distintos actores sociales, incluido el gobierno. El Estado, así, es el producto de estructuras reiteradas a lo largo del tiempo, como también de las estrategias de las fuerzas sociales que pueden desbordar las restricciones estructurales. En ese sentido, no todos los momentos históricos están igualmente abiertos al cabal reconocimiento de la territarias 45 241 
${ }^{1}$ En términos metodológicos, el artículo se asienta en una breve investigación exploratoria realizada a partir de la revisión de fuentes secundarias como documentos elaborados por los movimientos sociales ecologistas, documentos gubernamentales desde 2007 en adelante, articulos de investigación académicos y tesis de posgrado.

\section{territarias 45} 242 totalidad de los actores sociales, sus intereses e identidades (Jessop, 1982).

El movimiento discursivo-político que realizó el gobierno para dar por terminada la iniciativa Yasuní-ITT demostró que las selectividades inscritas en el terreno estatal jugaron un rol importante en la adopción de la decisión pública. Estas selectividades vinieron dadas por la necesidad del gobierno de contar con rápidos y cuantiosos ingresos fiscales para retomar su segundo mandato presidencial y continuar implementando su proyecto. La decisión de abandonar la Iniciativa Yasuní-ITT generó una multiplicidad de resistencias sociales, tanto en la Amazonía como en las principales ciudades del país, canalizadas a través de movilizaciones por parte de distintos colectivos ecologistas, especialmente urbanos, y organizaciones no gubernamentales; la creación de un colectivo llamado "Yasunidos"; y la realización de una campaña nacional de recolección de firmas para convocar a una consulta popular que anulara la decisión del gobierno. Este conflicto socio-ambiental reconfiguró la dinámica política y puso de manifiesto la multiplicidad de "lenguajes de valoración" (Svampa, 2008) en torno al desarrollo y al territorio, construidos y defendidos por los distintos actores en pugna: desde el gobierno, pasando por los diversos movimientos sociales ecologistas e indígenas, hasta organizaciones internacionales.

Este trabajo analiza, entonces, la disputa en torno al desarrollo y el territorio a partir de concentrarse en la política gubernamental conocida como Iniciativa Yasuní-ITT implementada desde 2007 hasta 2013 por el proyecto de la Revolución Ciudadana, liderado por Rafael Correa. El texto se enmarca en la discusión en torno al territorio como espacio conflictivo de poder y se estructura en dos partes. En primer lugar, se presentan los rasgos principales de la cuestión del Yasuní-ITT y los discursos en torno al territorio, su conservación o explotación antes de que emergiera la Iniciativa en 2007. En segundo lugar, se reconstruye brevemente la dinámica social del conflicto que emergió en 2013 a partir de la decisión gubernamental de explotar el Parque Nacional (abandonar la Iniciativa), identificando los distintos discursos alrededor de la problemática del desarrollo y del territorio que se construyeron como parte de la disputa socio-política. ${ }^{1}$ Por último, se esbozan algunas reflexiones en torno al territorio como campo de disputa y de configuración de relaciones de poder.

\section{"Moratoria petrolera", desarrollo y territorio: los discursos en torno a la conservación del Yasuní}

El Parque Nacional Yasuní se creó a fines de la década del setenta y en 1989 la UNESCO (por su sigla en inglés) lo declaró Reserva Mundial de Biosfera que, según la definición de la organización, constituye una zona de ecosistemas terrestres o costeros/marinos que cumple dos 
funciones: por un lado, la conservación de la diversidad genética, las especies, los ecosistemas y los paisajes, y por otro, el desarrollo económico y humano sostenible a través del apoyo de proyectos locales, regionales y nacionales de demostración, educación, capacitación e investigación. Desde ese año en adelante, los sucesivos gobiernos nacionales fueron modificando los límites de la extensión del territorio que comprendería el Parque Nacional, así como las extensiones de las tres zonas identificadas en él: la zona núcleo (espacio de protección de la diversidad cultural y biológica donde residen comunidades indígenas en estricto aislamiento), la zona de amortiguamiento (asentamientos colonos y de otras comunidades indígenas) y la zona de transición (allí se asientan poblaciones indígenas y mestizas, y existen pozos petroleros). Esta zonificación permitió identificar las áreas que debían ser conservadas y protegidas de la actividad petrolera (Dillon Madrid, 2012).

La delimitación de zonas responde a lo que Svampa ha denominado "zonificación de los territorios", política que se asocia a una noción de territorio relacionada con la idea de que este es susceptible de ser sacrificado. En palabras de la socióloga argentina,

la definición de patrones de uso de suelo apuntaría a definir qué territorios serían eximidos de la actividad extractiva, mientras que otros estarían disponibles para su recepción, todo lo cual remite claramente a la idea de 'territorio sacrificable' o 'áreas de sacrificio'. (Svampa, 2008, p. 9)

Si bien la UNESCO no menciona si las actividades extractivas están permitidas en esas zonas, se deduce que no, en la medida en que las reservas de biosfera deben adecuarse a un "desarrollo sostenible" y las actividades extractivas atentarían contra este (Fontaine, 2007).

A pesar de las diversas reglamentaciones para conservar el territorio y evitar su explotación petrolífera, así como las distintas intervenciones realizadas desde la década del noventa por el Ministerio de Ambiente de Ecuador, las actividades extractivas por parte de diversas empresas extranjeras, así como de empresas públicas, fueron sostenidas ininterrumpidamente desde el año que en fue declarado Reserva Mundial. Desde ese momento, la activación de una fuerte presión de distintos grupos ecologistas y de conflictos socio-ambientales con las comunidades indígenas que habitaban el territorio fue una constante. Si bien unos y otros rechazaban la explotación del territorio, los intereses $-\mathrm{y}$, por ende, los argumentos que defendían públicamente- eran diversos.

Para las comunidades, el mayor objeto de disputa de estos conflictos se vinculó más a la modificación de los límites territoriales y el problema de la autodeterminación territorial, que a los daños ambientales sobre el territorio. Los pueblos indígenas no contactados y nómadas que viven allí de forma voluntaria, no solo tersitarias 45 243 
2 Alberto Acosta es un economista y politico ecuatoriano vinculado al movimiento ecologista desde hace más de 20 años y uno de los idéologos del Movimiento Alianza Pais. Fue ministro de Energia y Minas durante el gobierno de la Revolución Ciudadana, así como presidente de la Asamblea Nacional Constituyente del Ecuador, de la cual renunció por discrepancias en el modo en que el Poder Ejecutivo, particularmente el ex Presidente Correa, estaba gestionando el proceso constituyente.

\section{territarias 45} 244 habitan en la zona declarada intangible - la denominada zona núcleo-, sino que se han venido trasladando año tras año de un lado al otro dentro del Parque (Álvarez Méndez, 2012). Asimismo, en el Parque Nacional Yasuní viven varios pueblos indígenas, además de aquellos en aislamiento voluntario. Uno de ellos, los Waoranis, tienen un territorio legalmente reconocido que representa otra zona del Parque Nacional.

En este sentido, las sucesivas definiciones de nuevos límites territoriales, a las que nunca fueron convocados a participar, los han perjudicado enormemente (Álvarez Méndez, 2012). Se podría decir que el "control territorial" indígena ha sido escaso, si entendemos por este la capacidad para limitar el avance de la actividad petrolera y "aumentar el control indígena sobre la forma en que la actividad petrolera coloniza su territorio" (Cisneros, 2007). Esto puede ser leído como un conflicto ontológico, en la medida en que la racionalidad occidental colisiona con otro tipo de racionalidades. Aquella separa la naturaleza de la sociedad e instrumentaliza las relaciones con el territorio y con el medioambiente. Por fuera de ese paradigma cognitivo, existen otras ontologías que comprenden las relaciones entre humanos y el territorio de forma interrelacional, horizontal y orgánica. Desde esta concepción, el territorio, las personas que ancestralmente lo habitan y las demás especies, forman parte de un todo indivisible y armónico. De manera concreta, la primera forma delimita al territorio de manera cartesiana con una línea imaginaria sobre el suelo para realizar un fin determinado, mientras que, para la segunda, el territorio es una continuidad de todas las especies que lo habitan, e inversamente, los que lo habitan son una extensión del territorio, es decir, una visión ontológica sin fragmentaciones (Ingold, 2000; Descola, 2001; Latour, 2015; Escobar, 2016).

En los años noventa, esta preocupación por la delimitación territorial en tanto bandera que levantó el movimiento ecologista - especialmente portada por distintas organizaciones no gubernamentales como Acción Ecológica y Pachamama- comenzó a enfatizar en los impactos socio-ambientales que implicaba la explotación del parque. Desde estos grupos ambientalistas se propuso lo que se conoció como la "moratoria petrolera", es decir, colocar un freno a las actividades extractivas en el oriente ecuatoriano ya que la renta generada por la explotación de esos recursos no solo no favorecía al desarrollo social del país ni a las áreas que estaban siendo explotadas, sino que estaba provocando un deterioro del tejido social, del entorno natural y de la biodiversidad excepcional que anida en él (Acosta \& Martínez, 2010). ${ }^{2}$

Hay que mencionar que el arco de colectivos y organizaciones que ha conformado el movimiento ecologista es muy amplio y heterogéneo, por lo tanto, no es posible considerarlo como un sujeto 
homogéneo, sino que en su interior convergen diversas visiones y proyectos en torno al desarrollo y medio ambiente (Álvarez Méndez, 2012): aquellas que portan el reclamo de las comunidades campesinas e indígenas del norte amazónico por reparaciones e indemnizaciones debido a la contaminación generada por las actividades petroleras desde los años 70; aquellas que, representadas mayormente por las ONG, se oponen a la exploración y explotación petrolera en áreas protegidas; y aquellas que provienen de las propias comunidades afectadas y rechazan la expansión de actividades extractivas en sus territorios (Dillon Madrid, 2012).

Más aún, dentro del arco de las comunidades indígenas, subyacen distintas posturas, unas más radicales que abogan por la no explotación, de modo rotundo, y otras que, siendo moderadas y pragmáticas, defienden una explotación parcial, siempre y cuando esto sea negociado con las comunidades, así como acordado el reparto de las ganancias. Esta tensión entre distintas posturas comunitarias aflorará nuevamente cuando el gobierno de Correa anuncie la decisión de explotar el Yasuní.

De todos los discursos que circularon desde los años 90, la propuesta de la "moratoria petrolera" fue la que logró calar profundamente no solo entre la ciudadanía de clase media sino particularmente en el proyecto gubernamental desde 2007. Estos discursos estuvieron muy ligados, a su vez, a enfoques globales que comenzaron a postular las ideas de decrecimiento y de postdesarrollo de la mano de intelectuales neomarxistas ecológicos como O'Connor (2001), Latouche (2006) y Arturo Escobar (2005). La idea de moratoria petrolera quedó plasmada en distintos documentos y en el libro El Ecuador postpetrolero (Acosta, 2000). Esa iniciativa germinó en el seno de la llamada sociedad civil en conjunto con algunos de los que luego serán funcionarios del gobierno de Correa. Esta propuesta cristalizó en lo que se conoció desde 2007 como Iniciativa Yasuní-ITT (Le Quang, 2013). Sin embargo, dicha iniciativa estuvo desvinculada de las comunidades indígenas que habitan el territorio. Las ONG asumieron la representación de las poblaciones del Yasuní, pero estas no fueron consultadas sobre su preferencia en torno a explorar o no el territorio. Así, la construcción de una multiplicidad de territorialidades alrededor de la cuestión del Yasuní, es decir, diversos modos en que grupos y sujetos sociales se apropian del territorio, lo controlan y ponen en juego formas de ser, de saber y de poder (Lopes de Souza, 1995), comenzó a ser la pauta regular.

Para los pueblos indígenas de la Amazonía, el territorio "les ha permitido desarrollar y reproducir los aspectos sociales y culturales para su subsistencia, asegurando formas de control del espacio especiales y compatibles con la organización política del Estado y que son concebidas precisamente a partir de ésta" (Hvalkof \& territarios 45 245 
Plant, citado en Cisneros, 2007, p. 136). Este tipo de territorialidad denota un tipo de comportamiento en el espacio físico y de pertenencia social a la tierra, que entra en oposición a la territorialidad construida y portada por otros actores sociales (ONG), económicos (empresas tanto transnacionales como estatales) y por los gobiernos que ocuparon el Estado hasta 2007. En efecto, tal como sostienen los trabajos de Bebbington (2009), existe un variopinto conjunto de actores que intervienen en diferentes escalas y operan en redes (Tsing, 2004). Estos actúan en los conflictos socio-territoriales, en la disputa por enmarcarlos discursivamente (en torno a conceptos como extractivismo, sostenibilidad, conservación, etc.), en la lucha por los intereses particulares de cada quien y en la dirección de los procesos nacionales de desarrollo. Esos actores van desde las empresas privadas $\mathrm{y}$ transnacionales, los gobiernos, las ONG (nacionales e internacionales), los Estados en tanto espacios institucionales y reguladores de las pautas de acción, las comunidades indígenas o asentadas en determinados territorios, los movimientos sociales y grupos de activistas, colectivos de derechos humanos, inversionistas y bolsas de valores.

A su vez, estos heterogéneos actores se han inscrito, desde los años ochenta, en diferentes enfoques que cuestionan la noción de desarrollo, algunos de ellos con una fuerte crítica al paradigma de la modernidad y modernización (Svampa,
2016). Desde entonces, comienzan los estudios en torno al desarrollo sustentable, en dos variantes: en clave "fuerte" de parte de la ecología política y los movimientos sociales, y en una clave "débil" por parte de las corporaciones y organizaciones internacionales. Este debate se reactualiza en el siglo XXI en el contexto de los gobiernos progresistas y el boom de los commodities.

En esta línea, para las ONG, el territorio del Parque Yasuní, en particular, y el de la selva amazónica, en general, deben ser conservados en pos de garantizar la sostenibilidad del medio ambiente, en tanto espacio físico que contiene biodiversidad y es el soporte físico de grupos humanos. Varias de estas ONG encarnan el discurso defendido por las propias comunidades que se asientan, como hemos señalado más arriba, sobre un principio ontológico antagónico al occidental dominante (Svampa, 2016) según el cual no existe tal separación entre lo humano y la naturaleza (Descola, 2001), ni tampoco distinción posible entre valor de uso y valor de cambio, tan bien desarrollada por el marxismo.

Para las empresas, el territorio amazónico siempre ha sido considerado un espacio útil que puede ser mercantilizado, privatizado o corporativizado (Silveira, 2007) (empresas privadas) o explotado para lograr crecimiento económico (empresas estatales) (Fontaine, 2007) Respecto al Estado, el territorio fue adquiriendo distintos sentidos y atribuciones según los 
distintos gobiernos que se fueron sucediendo. Por lo general, desde la década del ochenta, cuando el Yasuní fue creado en tanto Parque Nacional, los gobiernos procuraron mantener algunas áreas dentro de él bajo conservación con el argumento de preservar el medio ambiente, en una línea discursiva similar a la esgrimida por las ONG. Esta línea se inscribió también en el paradigma del multiculturalismo que abogaba por una moderada y controlada participación de los pueblos indígenas. En palabras de Cisneros,

la primera y fundamental distinción entre la conservación basada en la comunidad y las áreas conservadas por el Estado se establece porque los recursos naturales bajo el control de las comunidades, con baja intervención estatal y una incorporación al mercado no basada en la búsqueda de la acumulación, son usualmente manejados de acuerdo a reglas que privilegian la sostenibilidad de su sobrevivencia, la aversión al riesgo, la flexibilidad, la reciprocidad social y varios valores de uso. El paisaje resultante de esto es un patrón (tipo mosaico) de unidades de recursos bajo diferentes usos y regulaciones. En contraste, las áreas protegidas por el Estado privilegian la conservación de la biodiversidad, los lugares de hábitat y la estabilidad, la autoridad legal y los valores de mercado (Borrini Fereyabend, 2002: 5-6). (Cisneros, 2007, p. 138)

Sin embargo, los planteamientos dicotómicos apoyados en la defensa de la conservación (respaldada por las comunidades) frente a la defensa de la explotación (respaldada por empresas del sector privado e incluso por algunos gobiernos identificando zonas de conservación) son reduccionistas al parcializar el análisis, solo prestar atención a un componente del discurso o incluso otorgar cualidades normativas a uno u otro actor social, como romantizar la supuesta disposición conservacionista de las comunidades amazónico-indígenas sin adentrarse en proceso social, cultural y político "realmente" existente. Varias investigaciones revelaron que distintas comunidades que habitan el parque nacional (por ejemplo, una de las fracciones de los Waorani, los llamados "contactados", representados por la Organización Nacional Waorani del Ecuador), reconocen la necesidad de que las actividades petroleras se desarrollen en sus territorios para obtener ciertos beneficios y servicios, como infraestructura, educación y transporte, pero colocando ciertos límites (Narváez, 2013). Un caso paradigmático de la encrucijada conflictiva entre explotar o no, fue el que sufrió y aún sufre la comunidad "Llanchama" que llevó a divisiones profundas entre sus habitantes. Por un lado, parte de la comunidad respaldaba la explotación de la empresa Petroamazonas, mientras que la otra parte negaba esta posibilidad respaldada por el colectivo ecologista "Yasunidos" (Giménez, 2016). En algún punto de estas diferentes posiciones se revela que las comunidades necesitan territarias 45 247 
3 La Constitución estipuló un "Régimen de Transición” según el cual debian aprobarse dieciséis leyes en el lapso de un año en torno a distintos campos de politica pública. Varias de esas leyes estaban orientadas a fortalecer al Estado y a obtener mayores márgenes de autonomía estatal frente a una variedad de actores e intereses.

territarias 45 248 algún tipo de actividad económica - en el caso de Ecuador, la actividad extractiva petrolera- para tener acceso rápido a dichos bienes y servicios que el Estado no provee por diversos motivos. Aquí surge el otro gran - y tan antiguodebate en torno al progreso-desarrollo y las opciones reales abiertas para cambiar el sentido del "progreso" impuesto desde Occidente. Asimismo, se abre la discusión, que por cuestiones de espacio aquí no podemos abordar, acerca de los reales alcances que la actividad extractiva en la región latinoamericana tiene sobre el desarrollo endógeno, en la medida en que dicha actividad continúa ligada a la lógica del capitalismo dependiente con todas las dinámicas ya conocidas (externalización de los costos, expoliación de los territorios, etc.)

\section{Revolución Ciudadana: el paradigma del buen vivir y la iniciativa Yasuní-ITT}

En contraposición a las décadas de implantación del modelo neoliberal, cuando el Estado se retiró de la planificación del desarrollo y sugió la necesidad de que el desarrollo viniera "desde abajo" (García Delgado \& Casalis, 2006), durante la etapa que inicia con la llegada de Rafael Correa al gobierno del Ecuador, se da un proceso inverso: es ahora el Estado quien "desde arriba" plantea propuestas de desarrollo activando algunas tensiones con distintos actores sociales, pasando por momentos de reconocimiento de las alternativas formuladas por algunos movimientos, como el indígena, que fueron recuperadas en la Constitución de 2008, así como su invisibilización a lo largo del proceso político, especialmente desde la implantación del Régimen de Transición ${ }^{3}$ (Ramírez Gallegos, 2012). Al igual que en otros países de la región, como Argentina, Brasil, Venezuela y Bolivia, Ecuador se enmarca en el ciclo postneoliberal (Stoessel, 2014) a partir del cual se deja atrás un modelo económico aperturista, de ajuste estructural, endeudamiento y destrucción del aparato productivo. Desde ese momento se activa un nuevo modelo productivista, algunos lo denominarán "neo-desarrollista" (Bresser Pereira, 2007) con eje en la generación de empleo (García Delgado \& Casalis, 2006) a través del fortalecimiento del mercado interno y los procesos desarrollistas basados en la intensificacion de los sectores estratégicos, como hidrocarburos, agua, minería y energía.

La llegada a la presidencia de Correa, del movimiento político Alianza País (AP), significó un punto de inflexión respecto a la cuestión del Yasuní. El Plan de Gobierno que elaboró AP para el período 20072011 contempló la "moratoria petrolera" y estipulaba lo siguiente:

en este empeño por repensar la política petrolera, aparece con creciente fuerza la necesidad de analizar con seriedad en la posibilidad de una moratoria de la actividad

Soledad Stoessel, Martín Scarpacci 
petrolera en el sur de la Amazonía ecuatoriana, atada a una suspensión del servicio de la deuda externa. Sería imperdonable que se reedite la destrucción ambiental y social experimentada en el norte de la Amazonía. Además, es preciso manejar el petróleo existente como una reserva energética para el futuro, a ser extraída posteriormente, siempre que existan suficientes garantías para no poner en riesgo la principal riqueza de la Amazonía: su biodiversidad. (Alianza País, 2006, p. 47)

La moratoria petrolera se tradujo en la propuesta llamada "Iniciativa YasuníITT" que incluso tenía aspiraciones más radicales que aquella propuesta inicial de la moratoria. La iniciativa consistía en la decisión de no explotar un sector del Parque Nacional Yasuní. Dicho sector se componía de los cuadrantes de exploración petrolero llamados Ishpingo, Tiputini y Tambococha (ITT) (conocido como Bloque 43) y de una zona declarada intangible en 1998 (es el territorio delimitado por los pueblos indígenas en aislamiento, los pueblos Tagaeri y Taromenane). El objetivo de la propuesta era mantener el $20 \%$ de las reservas de petróleo del país bajo tierra ${ }^{4}$ a cambio de una contribución financiera internacional del $50 \%$ de lo que Ecuador hubiera obtenido en caso de explotarlo basándose en un principio de corresponsabilidad ambiental. ${ }^{5}$ La otra mitad sería asumida por el país constituyéndose en el principal contribuyente. Con esta propuesta, desde el discurso oficialista se aspiraba a reducir los impactos nocivos sobre el medio ambiente y el clima a nivel mundial, conservar la biodiversidad - en la nueva Constitución de 2008 se reconocerían los derechos de la naturaleza-, ${ }^{6}$ respetar a los pueblos indígenas que se mantienen allí en aislamiento voluntario y transitar hacia una sociedad postpetrolera. Esto suponía una toma de posición respecto a las estrategias que debían adoptarse para transformar la matriz productiva con una vocación superadora del desarrollo capitalista de los países "periféricos" basado en la explotación de los recursos naturales. La iniciativa encontró eco en parte del elenco y del proyecto gubernamental. Asimismo, tuvo gran repercusión en la opinión pública nacional e internacional (Le Quang, 2013) y tuvo una importante acogida en las organizaciones internacionales al reconocer la existencia de un problema ambiental global de envergadura y de la necesidad de contar con alternativas ante la amenaza del cambio climático. Esta alternativa de no explotación fue llamada "Plan A".

Por el contrario, también existía el denominado "Plan B" que consistía en explotar el Parque Nacional (se definieron cuatro modos de explotación) y quedó planteado en caso de que el Plan A no funcionara. En una economía que depende mayormente de la explotación y exportación de los recursos naturales, como el petróleo, esta iniciativa lucía absurda e inviable para algunos sectores de la sociedad
${ }^{4}$ Esto representa $846 \mathrm{mi}$ llones de barriles de reservas probadas de crudo de los campos ITT (Ramirez, 2012).

5 El $50 \%$ equivale a $\$ 3.600$ millones de dólaresen un plazo de 13 años, valor calculado según el número de barriles de las reservas probadas y el precio referencial del crudo (Ramirez, 2012).

${ }^{6}$ La Constitución de 2008 fue innovadora en varios sentidos, especialmente en torno al reconocimiento de los derechos de la naturaleza articulados al principio del Buen Vivir. La categoria de Naturaleza fue equiparada a la de Pachamama (art. 71), por lo que se resalta la importancia de los saberes $y$ valores indigenas, una definición no instrumentaly no antropocéntrica de la Naturaleza la cual pasa a convertirse en sujeto de derecho y una ruptura con la idea convencional de desarrollo (Gudynas, 2011): "La naturaleza o Pacha Mama, donde se reproduce y realiza la vida, tiene derecho a que se respete integralmente su existencia y el mantenimiento y regeneración de sus ciclos vitales, estructura, funciones y procesos evolutivos. Toda persona,

\section{$\Longrightarrow$}

territarios 45

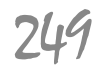


$\Longleftarrow$

comunidad, pueblo o nacionalidad podrá exigir a la autoridad pública el cumplimiento de los derechos de la naturaleza. El Estado incentivará a las personas naturales $y$ juridicas, y a los colectivos, para que protejan la naturaleza, y promoverá el respeto a todos" (Const., 2008, art. 71).

${ }^{7}$ Datos extraidos del Banco Central del Ecuador: https://www.bce.fin.ec

${ }^{8}$ Este porcentaje se modificó una vez que el gobierno de Correa construyó algunas centrales hidroeléctricas. Para el año 2016, se habian inagurado tres hidroeléctricas (Coca-Codo Sinclair, Manduriacu y Sopladora) y desde entonces el $57 \%$ de la generación eléctrica comenzó a provenir de fuentes hidricas.

${ }^{9}$ La nueva Constitución establece derechos colectivos para los pueblos y nacionalidades indigenas tales como "participar en el uso, usufructo, administración y conservación de los recursos naturales renovables que se hallen en sus tierras [...] la consulta previa, libre e informada, dentro de un plazo razonable, sobre planes $y$ programas de prospección, explotación y comercialización de recursos no

$\Longrightarrow$

territarias 45 y para ciertos grupos dentro del gobierno, incluso para el propio presidente, quien en varias oportunidades expresó la necesidad de colocar tiempo límite para lograr recaudar esa compensación internacional ("Ecologistas cuestionan...", 2011). Hay que tener en cuenta que para el año 2010, el $56 \%$ del total de exportaciones ecuatorianas provenía del crudo y derivados y el $30 \%$ de ingresos del presupuesto general del Estado provenían del petróleo. ${ }^{7}$ Asimismo, cabe mencionar que, gran parte del financiamiento de la política social procedía por entonces de la renta generada por la actividad petrolera y el $80 \%$ del suministro energético del país era aportado por este hidrocarburo. ${ }^{8}$ En ese sentido, en palabras de Fontaine (2007), existe una tensión entre el desarrollo económico y social basado en la extracción de petróleo y la intención de proteger el medio ambiente.

La iniciativa Yasuní se apoyó en tres discursos y diagnósticos distintos. Las ONG que se presentaban como portavoces de las comunidades consideraban que esta iniciativa estaba vinculada a un problema público relacionado con los daños socio-ambientales generados por las actividades extractivas. La noción de territorio que subyacía era aquella que asociaba al territorio como soporte físico y bio-diverso que debe ser resguardado. Abanderaban, en general, un discurso que Svampa, retomando la definición de Joan Martínez Alier (2004), ha denominado "eco-eficientista", es decir, "el énfasis en el cuidado del medio ambiente y la búsqueda de un desarrollo que no hipoteque el futuro de las generaciones venideras". Para ello proponen "el uso eficiente de los recursos naturales y el control de la contaminación” ('desarrollo sustentable', 'industrias limpias').

Las comunidades indígenas, por su parte, portaban otro sentido del territorio. Lo conceptualizaban como espacio de hábitat y comunidad de vida, y sobre esa concepción reclamaban por sus derechos territoriales reconocidos en la nueva Constitución ecuatoriana. ${ }^{9}$ El discurso de las comunidades indígeno-amazónicas es parcialmente distinto a las ONG antes mencionadas y se puede enmarcar en lo que Martínez Alier ha denominado "ecología popular". Con ello se refiere a una corriente que pone el énfasis en los conflictos ambientales generados por la reproducción del capital, la división territorial del trabajo y el desplazamiento geográfico de las fuentes de recursos naturales presionado por los países desarrollados que repercute especialmente en las poblaciones pobres y excluidas de los países periféricos. Según varias investigaciones desarrolladas en el territorio del Parque Yasuní y que han trabajado directamente con las comunidades que allí habitan, la noción de territorio que defienden las comunidades indígenas es distinta a la defendida por otros actores sociales, como las ONG y los gobiernos que han antecedido. Así, para la concepción indígena 
el territorio es concebido como el espacio en el que la vida se construye y es además un proceso formativo [...] que va dejando una herencia, un rastro [...] define un modo de vivir que no tiene necesariamente límites físicos. Es más, una memoria en la que se juntan varias capas de entendimiento del espacio en el que se forma la vida. (Cisneros, 2007, p. 134)

Por su parte, el discurso del gobierno fue un tanto más complejo y ambiguo dado que albergó distintas corrientes. La Constitución de 2008 definía al régimen de desarrollo como:

el conjunto organizado, sostenible y dinámico de los sistemas económicos, políticos, socio-culturales y ambientales, que garantizan la realización del Buen Vivir o sumak kawsay [...] el buen vivir requerirá que las personas, comunidades, pueblos y nacionalidades gocen efectivamente de sus derechos, y ejerzan responsabilidades en el marco de la interculturalidad, del respeto a sus diversidades, y de la convivencia armónica con la naturaleza. (Const., 2008, art. 275)

Si bien la definición era clara, el proyecto de la RC contenía distintas posturas en torno al desarrollo y asociado a este, alrededor del territorio.

Por un lado, dentro del gobierno, existía un sector más desarrollista de tipo convencional, es decir, vinculando al desarrollo a partir de una visión moderna-productivista. Esto significaba que, si bien se reconocía el respeto a la naturaleza, el territorio debía ser utilizado para emprender procesos de desarrollo capaces de mejorar las condiciones de vida de las y los ecuatorianos. Esta postura era la que se expresaba en el Plan B del Yasuní. Por otro lado, se encontraba una vertiente de tipo bio-céntrica asociada a un desarrollismo sustentable ${ }^{10}$ que postulaba la necesidad de avanzar en alternativas al capitalismo para construir un nuevo orden social. Este enfoque también era promovido por ciertas figuras políticas dentro del gobierno, cercanas a una concepción de la idea de Buen Vivir, pero no ligada a las cosmovisiones indígenas. En algún punto, esta concepción continuaba inscrita en el paradigma moderno (Cubillo-Guevara et al., 2014). Este tipo de discurso se proponía como una alternativa crítica al problema de la sustentabilidad en la región latinoamericana y en especial en Ecuador. Asimismo, especialmente el nuevo programa del movimiento Alianza País en 2013, introdujo una nueva semántica al asociar el Buen Vivir con el socialismo con el objetivo de

articular la lucha por la justicia social, la igualdad y la abolición de los privilegios, con la construcción de una sociedad que respete la diversidad y la naturaleza. En tal sociedad podremos desarrollar nuestras capacidades y vivir digna y libremente. El fin del Socialismo del Buen vivir es defender y fortalecer la sociedad, el trabajo y la renovables que se encuentren en sus tierras y que puedan afectarles ambiental o culturalmente; participar en los beneficios que esos proyectos reporten y recibir indemnizaciones por los perjuicios sociales, culturales y ambientales que les causen. La consulta que deban realizar las autoridades competentes será obligatoria y oportuna. Si no se obtuviese el consentimiento de la comunidad consultada, se procederá conforme a la Constitución y la ley. Conservar y promover sus prácticas de manejo de la biodiversidad $y$ de su entorno natural. El Estado establecerá y ejecutará programas, con la participación de la comunidad, para asegurar la conservación y utilización sustentable de la biodiversidad [como también a] no ser desplazados de sus tierras ancestrales" (Const., 2008, art. 57).

${ }^{10}$ René Ramirez Gallegos, ex secretario nacional de Planificación y ex secretario nacional de Educación Superior, Ciencia, Tecnología e Innovación, ha denominado a esta postura "biosocialismo del sumak kawsay o republicano" (Ramirez, 2012).

\section{territarias 45}


${ }^{11}$ En el siguiente enlace se encuentra el discurso completo de Rafael Correa cuando anuncia la finalización de la Iniciativa Yasuni: https:// ww woutube.com/ watch? $v=5 x \operatorname{lq} v H D v A w I$.

\section{territarias 45}

vida en todas sus formas. El primer paso es resolver el acceso a bienes, oportunidades y condiciones que garanticen -al individuo, a la colectividad y a las generaciones futuras- una vida digna sin perjudicar a la naturaleza. (SENPLADES, 2009, p. 24).

La decisión de no explotar el Yasuní - el Plan A - se inscribía en esta perspectiva porque se proponía como una forma de superar en el largo plazo al neoliberalismo y al capitalismo. Esta alternativa priorizaba el valor de uso por sobre el valor de cambio (propio de la lógica capitalista) de los territorios, la primacía de la vida por sobre el lucro como valor último de la economía (Coraggio, 2009) y otro modo de pensar el desarrollo y el territorio, no asociado a las lógicas de acumulación que propone el capitalismo. En ese sentido, el modo de gestionar el territorio (en el caso del Plan A) es un factor de cambio social (Santos, 1996).

Si bien esta postura fue la que primó durante el período 2007-2013, en agosto de 2013 el presidente Correa, a través de una cadena nacional, anunció la decisión de comenzar a implementar el Plan B. Varios fueron los argumentos para explotar el Yasuní, pero principalmente primaron dos: por un lado, la nula cooperación de los países centrales y su visión de un "uso corporativo", particularista y lucrativo, de los territorios y del medio ambiente (Silveira, 2007). Ante la ausencia de la contribución financiera internacional esperada para sostener la iniciativa Yasuní que, desde sus fundamentos, se había planteado como una propuesta multi-escalar, es decir, que no solo estaba dirigida a preservar el territorio nacional ecuatoriano, sino la biodiversidad y el clima a nivel mundial (dado los efectos positivos de la no emisión de $\mathrm{CO}_{2}$ ), el gobierno nacional decidió que de ese modo ya no era viable. Y el segundo argumento, concomitante con el anterior, se apoyó sobre la necesidad de que un país subdesarrollado como Ecuador cuente con recursos que puedan contribuir a salir de la pobreza: "no podemos vivir como mendigos sentados en un saco de oro", fue la frase célebre con la que Correa anunció la decisión de explotar el territorio amazónico. ${ }^{11}$

Al anunciar esta decisión, el presidente posicionó públicamente un dilema: ‘hasta qué punto la no explotación del Yasuní beneficia ciertos intereses particulares - las pocas comunidades indígenas que allí habitan, los colectivos ecologistas que reivindican el respeto a los derechos de la naturaleza- $y$, por el contrario, termina por perjudicar a las grandes mayorías que podrían beneficiarse de las ganancias obtenidas de su explotación "sustentable" para mejorar sus condiciones de vida?

Este tipo de razonamiento en que los intereses particulares de los distintos actores sociales y sectores se contraponían al bien común fue la tónica que estuvo a la base de las explicaciones públicas que el gobierno enunciaba al momento de tomar decisiones políticas. Desde el primer momento, el gobierno emprendió una 
"batalla contra el corporativismo", esto es, desacoplar al Estado de los intereses particulares que portaban diversos sectores que durante décadas habían "capturado" las instituciones estatales. Para el gobierno, era fundamental recuperar al Estado que era el legítimo representante del bien común. Eso significó enfrentarse tanto a organizaciones sindicales - como de maestros-, el movimiento indígena en torno a los recursos naturales y la educación intercultural bilingüe, banqueros, cámaras empresariales, medios de comunicación, entre otros (Ramírez Gallegos \& Stoessel, 2015). Asimismo, implicó deslegitimar las demandas y revindicaciones que aquellos portaban. En nombre del interés general motorizado por el Estado, el gobierno adoptó una serie de medidas, entre ellas una política extractiva en la que no participaron activamente los actores afectados por ella, como las comunidades indígenas.

La explotación del territorio se postulaba como un mecanismo de inclusión social indirecto que, dadas las limitaciones estructurales que constriñen al desarrollo, lucía como una solución necesaria. Asimismo, se planteaba como una política indispensable para favorecer el desarrollo productivo y social (Casalis, 2011) en la medida en que, desde la visión oficialista, el extractivismo contribuiría en el mediano o largo plazo a salir del propio extractivismo, y, por tanto, a garantizar el bienestar de las mayorías.
Esta decisión estatal daba cuenta de otra dimensión del territorio y es la que algunos autores han denominado "territorio usado" (Santos, 1995), "territorio funcional o rentable a la acumulación capitalista" (Pradilla Cobos, 1997) o como "uso corporativo del territorio" (Silveira, 2007), esto es, el espacio geográfico como el conjunto solidario y contradictorio de sistemas de objetos y de acciones, que es utilizado de acuerdo a distintas técnicas y acciones políticas, que según las relaciones de poder marcan los usos de dicho territorio (Santos, 1991). Estas formas de entender al territorio denotan una dimensión estrictamente política en la medida en que involucra relaciones de fuerza y de poder, a diversos actores con intereses particulares que pugnan por ser dominantes en la gestión de los territorios $\mathrm{y}$ actores sociales que, pese a sus intereses, cooperan (Silveira, 2007). En palabras de Mabel Manzanal et al.:

el territorio sintetiza relaciones de poder espacializadas, relaciones entre capacidades diferenciales para transformar, producir e imponer acciones y voluntades, sea bajo resistencia o no, bajo conflicto o no. Y esto no es más que reconocer que la producción social del espacio es un resultado del ejercicio de relaciones de poder. $(2007$, p. 33$)$

El conflicto socio-político que inició a partir de agosto de 2013, y que continúa hasta nuestros días durante el 
12 Por exceder el recorte temporal de este trabajo, no desarrollamos aqui la nueva fase que se inicia con el nuevo gobierno de Moreno que lejos de retroceder con la decisión de explotar el Yasuni, la institucionalizó aún más al convocar a una consulta popular en febrero 2018 que incluyó dos preguntas referidas a la cuestión.

territarias 45 gobierno de Lenín Moreno, ${ }^{12}$ en torno al Yasuní-ITT fue una contienda que, en efecto, puso sobre el tapete las disputas en torno al territorio, por el territorio y por su definición. Como asevera Manzanal et al. (2007), para estudiar la naturaleza de un territorio no hay que analizar sus características geográficas y ecológicas sino, fundamentalmente, los actores que lo dominan y cómo lo hacen. A partir de ese momento, una multiplicidad de acciones de protesta se irrigó no solo en los territorios de la Amazonía sino en las principales ciudades de Ecuador. Durante los años previos, varias habían sido las expresiones públicas de diversos colectivos y movimientos en defensa de la Iniciativa, sobre todo en ciertos momentos en que, desde el gobierno, se anunciaba la posibilidad de abandonar la Iniciativa ("300 ecologistas infantiles...", 2010).

Los actores sociales de la contienda fueron heterogéneos, resaltando los movimientos ecologistas urbanos que encarnaban, en alguna medida, la representación de las comunidades indígenasamazónicas que habitan dicho territorio. Asimismo, la CONAIE, el movimiento indígena ecuatoriano, se plegó a la resistencia encabezada por los ecologistas anunciando un conjunto de movilizaciones bajo la consigna también dicotómica - aunque invirtiendo la carga valorativa de cada término- de la defensa del conservacionismo/buen vivir versus la explotación. Por último, se creó el colectivo
"Yasunidos" que convocó a recolectar firmas para llamar a una consulta popular, tal como habilita la Constitución en su artículo 57, para dar marcha atrás con la decisión gubernamental de explotar el territorio amazónico. Además, aprovechó esta coyuntura para posicionar públicamente el debate en torno al modelo de desarrollo (Silveira et al., 2019). El colectivo tuvo distintas expresiones locales en diversas ciudades. Estas resistencias portaron las banderas de la conservación del medio ambiente, así como del respeto a los derechos humanos de las comunidades indígenas que habitaban dicho territorio. Sin embargo, pese a que "Yasunidos" logró reunir las firmas, el Consejo Nacional Electoral anuló el procedimiento aduciendo haber hallado firmas viciadas, así como irregularidades en la recolección de las firmas. Tal como ha sucedido con distintos movimientos ecologistas en toda la región (Svampa, 2016), dicho movimiento se replegó en sus propias demandas (de clases medias urbanas) dejando a un lado los propios reclamos de las comunidades directamente afectadas, quienes, en algunos casos, sostuvieron la necesidad de que se explote su territorio para obtener ciertos beneficios a los que de otro modo no accederían. Esta situación puso en evidencia, pues, las ambigüedades y complejidades de los procesos de desarrollo en la región, y, más aún, la necesidad de superar los discursos antitéticos en torno al territorio. 


\section{Conclusiones}

Este trabajo tuvo como objetivo presentar el modo en que se gestó y desarrolló la disputa por el desarrollo y el territorio en Ecuador, a partir de una política gubernamental del proyecto político conducido por Rafael Correa conocida como “Iniciativa Yasuní-ITT". Esta política se mantuvo desde 2007 hasta 2013, cuando el gobierno decidió abandonarla, provocando un gran conflicto socio-político y ambiental. Dicho conflicto reflejó de modo paradigmático la premisa teórica de que el territorio constituye, entre otros aspectos, el terreno de disputa política y social por excelencia de las sociedades capitalistas contemporáneas.

El texto presentó cómo la llegada al poder político de un gobierno que fortaleció al Estado y a sus capacidades para regular la economía e intervenir en distintos sectores, gestionó de un modo específico el territorio y que el modo de gestionarlo no fue unívoco ni lineal, sino que atravesó distintos momentos durante el paso del Plan A al Plan B de la Iniciativa Yasuní, no solo demostró los constreñimientos estructurales a los que los países latinoamericanos deben hacer frente sino que las concepciones sobre el territorio y el desarrollo van mutando según condiciones estructurales, políticas y culturales.

La emergencia del paradigma del Buen Vivir y de los derechos de la naturaleza constitucionalizados en 2008 reforzó la propuesta innovadora de conservar bajo tierra el petróleo amazónico y contar con la contribución financiera de los países centrales. Ese cambio político-cultural fue viable hasta que las condiciones estructurales, nuevamente, colocaron ciertos límites. Para garantizar un régimen de bienestar que pueda responder a la amplitud de derechos constitucionalizados se requería un Estado fuerte y con abultados ingresos fiscales. Esta era la visión del gobierno. Luego de la crisis mundial de 2009, el Estado ecuatoriano logró recuperarse, pero aún seguía dependiendo de los ingresos del petróleo. ${ }^{13}$ En ese marco fue que el gobierno decidió en 2013 abandonar la Iniciativa YasuníITT y comenzar a explotar una parte del territorio. De esta forma, recurrió a la clásica solución capialista-dependentista: explotar los recursos naturales. Tal como sostiene Silveira, con frecuencia, "los partidos políticos, aun aquellos más progresistas o con buenas intenciones, proponen acciones que no dejan de ser subordinadas porque, entre otros aspectos, se ignora la forma de existencia en el territorio" (Silveria, M.L, 2007, p. 18). El conflicto por el Yasuní reveló, entre otras cuestiones, que el territorio, además de materializarse geográficamente y constituir el "soporte físico" donde habita la población y se desarrollan procesos productivos, es un constructo social y un espacio de poder que es apropiado por los sujetos
13 En efecto, en el año 2014 cuando el precio internacional de petróleo bajó considerablemente, el presupuesto general del Estado debió reducirse en un 20\% (Banco Central del Ecuador: https:// www.bce.fin.ec/). 
(Casalis, 2011). El territorio es objeto de disputa por diversos intereses particulares, aunque el Estado, posicionándose como el garante del interés general, tiene prerrogativas y "capacidades diferenciales" respecto a otros actores sociales para gestionar el territorio según diversos objetivos y racionalidades. Por otro lado, la exacerbación de la lógica de acumulación por despojo ha provocado en nuestros días "un punto de inflexión a partir del cual el territorio, en un sentido más amplio, esto es, concebido doblemente como hábitat y comunidad de vida, aparece en el centro de los reclamos de las movilizaciones y movimientos campesinos, indígenas y socioambientales" (Svampa, 2008, p. 11).

En efecto, esto fue así en Ecuador durante varias décadas en las que diversos movimientos, ONG, colectivos y comunidades indígenas se expresaron pública y conflictivamente en torno a una variedad de discursos acerca del territorio, el desarrollo y la "buena vida". Estos cobraron mayor visibilidad durante la coyuntura que se abre a mediado de 2013. Desde entondes, la disputa por los modelos de desarrollo, los - falsos- dilemas y argumentos (como el de conservación vs extractivismo; intereses particulares vs bien general, "preservar el medio ambiente es el interés de las comunidades", etc.) están a la orden del día no solo en Ecuador, sino en toda la región latinoamericana caracterizada por décadas de expoliación territorial y ambiental.

\section{Referencias}

300 'ecologistas infantiles' defienden al Yasuní. (2010, 14 de marzo). El Comercio. https://www.elcomercio. com/tendencias/300-ecologistasinfantiles-defienden-al.html

Acosta, A. (2000). El Ecuador post-petrolero. ILDIS.

Acosta, A., \& Martínez, E. (2010). ITTYasuni: entre el petróleo y la vida. Abya-Yala.

Alianza País. (2006). Plan de Gobierno del Movimiento País 2007-2011 [Propuesta en construcción colectiva]. http:// www.latinreporters.com/equateurRafaelCorreaPlandeGobiernoAlianzaPAIS.pdf

Álvarez Méndez, Y. (2012). Iniciativa Yasuni-ITT, un instrumento más de la contradicción estatal: un estudio de la politica de conservación desde la agenda pública (Tesis de maestría). FLACSO, Ecuador.

Bebbington, A. (2009). Industrias extractivas, actores sociales y conflictos. En J. Schuldt, A. Acosta, A. Barandiarán, M. Folchi, CEDlA-Bolivia, A. Bebbington, A. Alayza, \& E. Gudynas, Extractivismo, politica y sociedad (pp. 131-156). Centro Andino de Acción Popular (CAAP) de Ecuador; Centro Latino Americano de Ecología Social (CLAES).

Bresser Pereira, L. C. (2007). Estado y mercado en el nuevo desarrollismo. 
Nueva Sociedad, (210), pp. 110-125. https://nuso.org/articulo/estado-ymercado-en-el-nuevo-desarrollismo/

Casalis, A. (2011). Desarrollo local y territorial. Aportes metodológicos y teóricos para las políticas públicas. Revista de Ciencias Sociales, (19), 159-175. http://ridaa.unq.edu.ar/ handle/20.500.11807/1517

Cisneros, P. (2007). Los conflictos territoriales y los límites de la cogestión ambiental. En G. Fontaine \& I. Narváez (Coords.), Yasuni en el siglo XXI. El Estado ecuatoriano y la conservación de la Amazonia (Capítulo 3, pp. 136-181). Flacso Ecuador, IFEA, Abya Yala, PETROBRAS.

Constitución de la República del Ecuador [Const.]. 20 de octubre de 2008. Ecuador.

Coraggio, J. (2009). Territorio y economias alternativas. I Seminario Internacional Planificación Nacional para el Desarrollo Nacional, Visiones, La Paz.

Cubillo-Guevara, A. P., Hidalgo-Capitán, A. L., \& Domínguez-Gómez, J. A. (2014). El pensamiento sobre el Buen Vivir. Entre el indigenismo, el socialismo y el posdesarrollismo. Revista del CLAD Reforma y Democracia, (60), 27-58. https://www.redalyc. org/pdf/3575/357533692002.pdf

Descola, P (2001). Construyendo naturalezas: ecología simbólica y práctica social. En P. Descola, \& G. Pálsson (Coords.), Naturaleza y sociedad:pers- pectivas antropológicas (pp. 101-123). Siglo XXI.

Dillon Madrid, J. (2012). Yasuni-ITT: hacia un nuevo modelo de conservación y desarrollo sostenible (Tesis de maestría en Desarrollo económico y políticas públicas). Universidad Autónoma de Madrid.

Ecologistas cuestionan manejo de la iniciativa Yasuní-ITT. (2011, 28 de julio). El Comercio. https://www.elcomercio. com/actualidad/negocios/ecologistascuestionan-manejo-de-iniciativa.html

Escobar A. (2016, enero-abril). Sentipensar con la tierra: las luchas territoriales y la dimensión ontológica de las epistemologías del sur. Revista de Antropología Iberoamericana, 11(1), 11-32. http:// www.aibr.org/antropologia/netesp/ numeros/1101/110102.pdf

Escobar, A. (2005). El "postdesarrollo" como concepto y práctica social. En D. Mato (Coord.), Politicas de economia, ambiente y sociedad en tiempos de globalización (pp. 17-31). Facultad de Ciencias Económicas y Sociales, Universidad Central de Venezuela.

Fontaine, G. (2007). Problemas de la cooperación institucional: el caso del comité de gestión de la reserva de biosfera Yasuní. En G. Fontaine \& I. Narváez (Coords.), Yasuni en el siglo XXI. El Estado ecuatoriano y la conservación de la Amazonía (Capítulo 2, pp. 80-132). Flacso Ecuador, IFEA, Abya Yala, PETrobras. 
García Delgado, D., \& Casalis, A. (2006). El desarrollo local en el eje de la Politicas Social. Ministerio de Desarrollo Social de la Nación.

Giménez, J. (2016, 11 de julio). La comunidad amazónica de la reserva natural del Yasuní que acabó dividida por el petróleo. El Diario.es. https://www. eldiario.es/desalambre/comunidadamazonica-yasuni-dividida-petroleo_1_3908673.html

Gudynas, E. (2011). Desarrollo, Derechos de la Naturaleza y Buen Vivir después de Montecristi. En Debates sobre cooperación y modelos de desarrollo. Perspectivas desde la sociedad civil en el Ecuador (pp. 83-102). Centro de Investigaciones CIUDAD; Observatorio de la Cooperación al Desarrollo.

Ingold, T. (2000). Culture, Nature, Environment: Steps to an Ecology of Life. En The Perception of the Enviroment: Essays on Livelihood, Dwelling and Skill (pp. 13-26). Routledge.

Jessop, B. (1982). The Capitalist State: Marxist Theories and Methods. Martin Robertson \& Company Ltd.

Jessop, B. (2016). The State: Past, Present, Future. Cambridge \& Malden; Polity Press.

Latouche, S. (2006). Le pari de la décroissance. Fayard.

Latour, B. (2015). Face à Gä̈a. Huit conférences sur le nouveau régime climatique. La Découverte.

territarias 45

Le Quang, M. (2013). Dejar el petróleo bajo tierra. IAEN.
Lopes de Souza, M. (1995). O território: sobre espaço e poder, autonomia e desenvolvimento. En I. E. De Castro, P. C. Da Costa Gomes, \& R. Lobato Correa (Orgs.), Geofrafia: conceitos e temas (pp. 77-116). Bertrand Brasil.

Manzanal, M., Arzeno, M., \& Nussbaumer, B., (Comps.). (2007). Territorios en construcción. Actores, tramas y gobiernos: entre la cooperación y el conflicto. CICCUS.

Marini, R. (2008). Proceso y tendencias de la globalización capitalista (1997). En R. M. Marini (Comp.), América Latina, dependencia y globalización (pp. 247-271). CLACSO; Siglo del Hombre.

Martínez Alier, J. (2004). El ecologismo de los pobres. Conflictos ambientales y lenguajes de valoración. Icaria Antrazyt; FLACSO.

Narváez, I. (2013). Los waorani en el Yasuní: contrapoder de los poderes salvajes. En I. Narváez, I., M. De Marchi, M., \& S. E. Pappalardo (Coords.), Yasuni zona de sacrificio. Análisis de la iniciativa ITT y los derechos colectivos indigenas (pp. 29-55). FLACSO Ecuador.

O'Connor, J. (2001). Causas naturales. Ensayos de Marxismo Ecológico. Siglo XXI.

Porto-Gonçalves, C. (2009). De Saberes y de Territorios: diversidad y emancipación a partir de la experiencia latino-americana. Polis, 8(22), 121-136. https://doi.org/10.4067/S071865682009000100008

SOlEdAd Stoessel, MARTín SCARPACCI 
Pradilla Cobos, E. (1997). Regiones o territorios, totalidad y fragmentos: reflexiones críticas sobre el estado de la teoría regional y urbana. EURE, 23(68), 45-55. https://www.eure.cl/ index.php/eure/article/view/1155/0

Ramírez Gallegos, F. (2012). Reconfiguraciones estatales en Ecuador: 19902011. En M. Thwaites Rey (Ed.), El Estado en América Latina: continuidades y rupturas (pp. 341-373). Arcis; CLACSO.

Ramírez Gallegos, F., \& Stoessel, S. (2015). Campos de conflitividade política e movimentos sociais no Equador da Revolução Cidadã. Plural, Revista do Programa de Pós -Graduação em Sociologia da USP, 4-29.

Ramírez, R. (2012). Una gran transición para una gran transformación. Reflexiones a partir de la iniciativa Yasuní-ITT. En R. Blackburn, N. Frase, G. Therborn, \& R. Ramírez, Nuevas Fronteras de la Izquierda (pp. 135-153). IAEN.

Santos, M. (1991). O espaço: sistemas de objetos, sistemas de ações. En Anais do IV Encontro Nacional da ANPUR, Salvador de Bahía.

Santos, M. (1995). Metamorfosis del espacio habitado. Oikos; Tau.

Santos, M. (1996). La naturaleza del espacio. Técnica y tiempo. Razón y emoción. Ariel.

SENPLADES. (2009). Plan Nacional para el Buen Vivir 2009-2013: Construyendo un Estado Plurinacional e Intercultural [Plan Nacional de desarrollo]. https://www.planificacion.gob. ec/wp-content/uploads/downloads/2012/07/Plan_Nacional_para_el_Buen_Vivir.pdf

Silveira, M. L. (2007). Los territorios corporativos de la globalización. Geograficando, 3(3), 13-26. https://www. geograficando.fahce.unlp.edu.ar/article/view/GEOv03n03a0l/pdf_72

Silveira, M., Bayón M., \& Moreano, M. (2019). Resistencia multiescalar en el Yasuní: aportes desde la geografía crítica. En: M. Bayón, \& N. Torres (Eds.), Geografía critica para detener el despojo de los territorios: teorías, experiencias y casos de trabajo en Ecuador (pp. 103-115). Abya-Yala.

Stoessel, S. (2014). El giro a la izquierda en la América Latina del siglo XXI. Revisitando los debates académicos. Polis, 13(39), 123-149. http://dx.doi.org/10.4067/S071865682014000300007

Svampa, M. (2008). La disputa por el desarrollo. Territorios y lenguajes de valoración. En M. Svampa, Cambio de época. Movimientos sociales y poder politico (pp. 93-114). Siglo XXI.

Svampa, M. (2016). Debates latinoamericanos. Indianismo, desarrollo, dependencia y populismo. Edhasa.

Tsing, A. (2004). Friction: An Ethnography of Global Connections. Princeton University Press. 